\title{
Transcriptome-based identification and validation of optimal reference genes for quantitative real-time PCR normalization in Psathyrostachys huashanica
}

\section{Chuan Shen}

Northwest Agriculture and Forestry University

Jingyuan Li

Northwest Agriculture and Forestry University

Caiyan Wei

Northwest Agriculture and Forestry University

Xudong Zhang

northwest agriculture and forestry university

Yunfeng Wu ( $\nabla$ wuyunfeng@nwafu.edu.cn )

Northwest Agriculture and Forestry University https://orcid.org/0000-0002-8059-0842

\section{Research}

Keywords: Internal reference genes, Psathyrostachys huashanica, Gene expression, RT qPCR, Normalizat ion

Posted Date: March 29th, 2020

DOI: https://doi.org/10.21203/rs.3.rs-19569/v1

License: (c) (1) This work is licensed under a Creative Commons Attribution 4.0 International License.

Read Full License 


\title{
Transcriptome-based identification and validation of optimal reference genes for quantitative real-time PCR normalization in Psathyrostachys huashanica
}

\author{
Chuan Shen ${ }^{1}$, Jingyuan $\mathrm{Li}^{1}$, Caiyan $\mathrm{Wei}^{1}$, Xudong Zhang ${ }^{1}$ and Yunfeng $\mathrm{Wu}^{1 *}$ \\ Authors’email address; chuan_shen@qq.com, jinyuanli@nwafu.edu.cn, 1439205621@qq.com,
} 2522493232@qq.com

*Correspondence:wuyunfeng@nwafu.edu.cn

State Key Laboratory of Crop Stress Biology for Arid Areas, College of Plant Protection, Key Laboratory of Crop Pest Integrated Pest Management on Crop in Northwestern Loess Plateau, Ministry of Agriculture, Northwest A\&F University, Yangling 712100 Shaanxi, China

\begin{abstract}
Background:

P. huashanica (Psathyrostachys huashanica), known as an important resistance resource reservoir, is a rare and endangered plant growing suitably in Huashan mount region and would be urgently exploited in wheat genetic improvements sooner. During the utilization process, different IRGs (internal reference genes) need to be appropriately selected as standards based on biotic and abiotic stress conditions. It is crucial that Real-time RT-qPCR with combination of bioinformatics were adopted to explore the reliable IRGs from transcriptome of P. huashanica.
\end{abstract}

\section{Results:}

The present work reported new 3 species of IRGs, UBC2, UBC17, 18S $r R N A$, which were screened from transcriptome of P. huashanica under biotic and abiotic stress conditions, using RT-qPCR and four algorithms, including geNorm, NormFinder, BestKeeper, and RefFinder, to analyse expression of sixteen candidate reference genes. These genes appear as following $18 \mathrm{~S}$ rRNA (18S ribosomal RNA), EFI- $\alpha$ (eukaryotic elongation factor 1 alpha), UBC2 (ubiquitin-conjugating enzyme E2-2), UBC17 (ubiquitin-conjugating enzyme E2-17), $\alpha$-TUB2A 
(alpha tubulin-2A), $\beta$-TUB3 (beta tubulin 3), ADF4 (Actin-depolymerising factor 4), ACTIN (actin), GAPDH (Glyceraldehyde-3-phosphate dehydrogenase), 60SARP (60S acidic ribosomal protein), UBQ (polyubiquitin), SamDC (S-Adenosylmethionine decarboxylase), EIF4A (eukaryotic initiation factor 4A), ARF (ADP-ribosylation factor), HIS1 (histone H1), and HIS2B (histone $\mathrm{H} 2 \mathrm{~B}$ ). Analysis of gene expression demonstrated that the expression of $U B C 2$ gene was most stable under $\mathrm{ABA}$ hormone stress, low temperature stress and high temperature stress, similarly, $U B C 17$ gene under IAA hormone stress, salinity stress and drought stress, both $U B C 17$ genes and 18S rRNA genes under abiotic and biotic stress, respectively. The most stable gene was $U B C 2$ gene in the root, $U B C 17$ gene in stem and leaf. In this study, $\alpha-T U B 2 A, U B C$ and ACTIN genes were verified as the suitable reference genes across all tested samples. To further validate the suitability of the selected reference genes, we evaluated the relative expression of PsaCPK3 (Calcium-dependent protein kinase) and PsaHSP70-1 (heat shock protein 70-1), which are stress-related genes that may be involved in response to adversity.

\section{Conclusions:}

This study has identified a set of the most stable IRGs suiting for RT-qPCR detection of a few target gene expressions from P. huashanica in different experimental conditions. In addition, this study should provide the accuracy information for gene expression analysis in P. huashanica.

Keywords: Internal reference genes, Psathyrostachys huashanica, Gene expression, RT-qPCR, Normalization

\section{Background}

P. huashanica $(2 \mathrm{n}=2 \mathrm{x}=14, \mathrm{NsNs})$ is a new species of genus Psathyrostachys plants, and that is a rare and endangered plant growing suitably in Huashan mount region in China, known as an important resource reservoir of resistance to Barley yellow dwarf virus, wheat stripe rust wheat take-all, wheat fussarium head blight and drought. P. huashanica belongs to the genus Psathyrostachys, Triticeae of Poaceae, a wildly perennial relative of common wheat, and possesses numerous potentially valuable agronomic traits, such as tolerance to drought and salinity, resistance to stripe rust, wheat yellow dwarf virus and wheat take-all fungus [1-5]. Thus, in recent years, an increasing number of researchers have been studying these potentially valuable characteristics, which could be incorporated into common wheat [6]. Recently, a series of Triticum 
aestivum-P. huashanica Keng monosomic and disomic addition lines were created, and some stress response factors were identified at the molecular level to enhance disease resistance [7-8]. Understanding the expression patterns of stress response genes is the key to elucidate the mechanisms involved in various stresses of P. huashanica. Although some studies have been carried out on identification of gene function of P. huashanica, there have been no studies conducted for selecting suitable reference genes.

Real-time quantitative polymerase chain reaction (RT-qPCR) has become one of the most commonly used techniques to analyse mainly gene expression because of its high sensitivity, accuracy, convenience, reproducibility and specificity [9-11]. However, there are many variable factors could easily affected the accuracy of experimental data obtained by qRT-PCR, including differences in RNA sample quality, extraction method, reverse transcription efficiency and genomic DNA contamination [12-14]. Using suitable IRGs could help eliminate the variability introduced by different tissue samples and various experimental conditions, thus ensuring the accuracy and reliability of RT-qPCR results.

In previous studies, traditional housekeeping genes, such as GAPDH, 18S rRNA, ACT, EF1- $\alpha$, $\beta$-TUB, and UBQ, are often used as IRGs without evaluating the expression stability because of their indispensable role in maintaining plant growth and development in the face of different conditions [15-18]. They were assumed to be stably expressed in various tissues at different developmental stages and under a wide range of experimental conditions [19]. However, these traditional housekeeping genes have proved not to be always stably expressed in all tissues, development stages or experimental treatments [20-21]. The unstable expression of reference genes may affect final experimental results, thus leading to the deviation of target gene expression. Therefore, there is urgent need to select suitable reference genes that have stable expression levels under a variety of experimental conditions.

At present, several studies have been performed on the evaluation and validation of reference genes under biotic and abiotic stresses in a wide variety of plant species, such as Arabidopsis [22], rice [23], wheat [24], barley [25], Panax [26], soybean [27], melon [28], kiwifruit [29], pear [30], tomato [31] and cassava [32]. However, systematic evaluation of the selection of suitable reference genes for RT-qPCR data normalisation in P. huashanica under various experiments has not been reported. 
RNA-seq has become a powerful high-throughput tool for quantitative gene expression levels and exploring gene transcriptional regulation in different organisms under diverse conditions and treatments [33-34]. In previous studies, RNA-seq datasets have also been used to identify transcriptional changes under various abiotic and biotic stresses, and hence a series of stable expression reference genes were identified and validated by analysing the large data sets [35-37]. In this study, 16 reference genes (18S rRNA, EF1- $\alpha, \mathrm{UBC} 2$, UBC17, $\alpha$-TUB2A, $\beta$-TUB3, ADF4, ACTIN, GAPDH, 60SARP, UBQ, SamDC, EIF4A, ARF, HIS1, and HIS2B), were selected based on the RNA-seq datasets of P. huashanica. The expression stability of these selected reference genes was evaluated by RT-qPCR to identify potential reference genes suitable for target gene normalisation in experiments under abiotic conditions, including drought, salinity, cold and heat stress, hormonal stimuli (IAA and ABA) and biotic conditions, including fungal and viral inoculation in different plant tissues. Three software products (NormFinder, geNorm and BestKeeper) were used to systematically evaluate the qRT-PCR data, and the results were delivered to RefFinder for further analysis. Furthermore, the expression levels of two stress-related genes, PsaHSP70-1 and PsaCPK3, were conducted to validate the suitability of the selected reference genes. This work provides a series of suitable IRGs for future gene expression studies under different experimental conditions in P. huashanica.

\section{Results}

\section{Verification of the amplification efficiency and specificities of the primers for RT-qPCR}

We selected 16 protein-coding genes in $P$. huashanica as candidate reference genes for quantitative detection of mRNAs in leaf and stem tissue and 14 protein-coding genes in roots due to the low expression of GAPDH and SamDC genes. These gene names, corresponding primer sequences and expected product sizes are presented in Table 1, and the amplification specificities of these primers were confirmed by the melting curves which were shown as a single peak and all primers were amplified with a single band after agarose gel electrophoresis (Additional file 1: Fig. S1 and Fig. 1). We made standard curves using cDNAs with 10-fold gradient dilutions to get the amplification efficiency and the regression coefficient for each pair of primers. The amplification efficiency ranged from $75.22 \%$ to $100.73 \%$, and the regression coefficient ranged from 0.991 to 0.9994 (Table 1). 


\section{Expression level of the candidate reference genes in different treatments and different tissues}

The expression level of each gene was detected in corresponding tissues (leaves、 stems and roots) under different treatments (abiotic and biotic stress) by RT-qPCR technology. Lower CT values indicate high expression levels and good stability for the selected genes. Therefore, two candidate genes, GAPDH and $S A M D C$, were absent in the analysis of root tissues due to their high CT values. The average CT values of each gene ranged from 17 to 31 and all $\mathrm{CT}$ values were collected (Fig. 2 and Additional file 1: Table S1). The CT values indicated that transcription levels of reference genes are unstable under different experimental conditions.

\section{Expression stability of the candidate reference genes}

Different candidate genes have different expression levels in different plant tissues and under different stresses. To evaluate the expression stability of the candidate reference gens accurately, four programs (geNorm、NormFinder、Bestkeeper and refFinder) and Delta CT method were applied to the analysis, which suggest a stability ranking from the most expression-stable gene to the least stable gene (Additional file 2: Table S2).

Bestkeeper analysis. The rankings of the expression stabilities of the selected genes were variable in different tissues and treatments. Bestkeeper recommended reference genes expressing stably by $\mathrm{SD}$ and $\mathrm{CV}$ values. In abiotic stress treatments, the top five stable candidate genes in all tested samples under abiotic stress evaluated by Bestkeeper were $18 S, E L F 4 A, \beta T U B, U B C 2$ and $U B C 17$, and $18 S$ was the most stable gene (Table 2), whereas the two least stable genes were $\alpha T U B$ and $E F 1 \alpha$. In stem tissue, $18 S, E L F 4 A, U B C 2$ and $U B C 17$ were ranked as the top four most stable genes in different treatments. Bestkeeper suggested that $U B C 17, U B C 2, U B I$ and $A D F 4$ expressions were relatively stable in leave tissue, whereas the GAPDH and $60 S R P$ were evaluated as two least stable genes. Bestkeeper recommended a stability ranking of $18 S>A R F>U B C 2>$ $\beta T U B$ in root tissue. All the tested samples were classified into six abiotic treatments and one biotic treatments. In the IAA hormone-stressed treatment, $18 S$, ELF4A, HIS1 and ARF were selected by Bestkeeper as the most stable genes, and EFI $\alpha$ was the least stable gene. In the ABA hormone-stressed group, the stable gene ranking was $18 S>H I S 1>U B C 17>E L F 4 A>U B C 2$, while $E F 1 \alpha$ and $\alpha T U B$ were two least stable genes. For the heat-stressed treatment, Bestkeeper suggested that $18 S, E L F 4 A, \beta T U B$ and HIS1 were the four most stable genes, with $\alpha T U B$ and HIS4 ranked as the least stable genes. Expression stability ranking of candidate reference genes 
under cold, salinity stress and drought-stressed treatments are shown in Table 3 . The $18 S$ and $U B C 17$ genes were evaluated as the most stable ones in root, stem and leaf tissues, respectively, under biotic stress (Table 3). Additionally, we recommend the stability ranking under abiotic stress in different tissues, which is shown in Table 3.

GeNorm analysis. The geNorm program offered the optimal number of reference genes by calculating the pairwise variations $\mathrm{Vn} / \mathrm{Vn}+1$ to normalise the RT-qPCR data. The V2/3 value and V3/4 value (Fig. 3) in stem tissues under abiotic and biotic stress, respectively, was below the cut-off value of 0.15 , which means two of the most stable genes were suitable for normalising the qRT-PCR data under abiotic stress and three were suitable in the biotic stress treatment. The stability ranking calculated by the geNorm program is shown in Table 2, Table 3 and Additional file 2: Table S2.

Normfinder analysis. Results from the Normfinder program showed that the UBC17 and $18 S$ genes were the most stable genes under abiotic and biotic stress treatment, respectively. The expression stability rankings under different treatments in different tissues are shown in Additional file 2: Table S2.

RefFinder analysis. The RefFinder program is an online tool for normalising the RT-qPCR data, and it combines the results calculated by three other programs and finally presents the comprehensive expressional stability ranking for all selected genes. RefFinder recommended the gene expressional stability rankings of $U B C 2>\beta T U B>H I S 4>E L F 4 A$ and $U B C 2>A C T I N>U B I>U B C 17$ in roots under abiotic and biotic stress, respectively. In stem tissue, the rankings were $U B C 17>U B C 2>E F 1 \alpha>E L F 4 A$ and $18 S>A D F 4>E L F 4 A>A R F$ under abiotic and biotic stress, respectively. In leaf tissue, the expressional stability rankings under abiotic and biotic stress were $U B C 17>E L F 4 A>U B C 2>\beta T U B$ and $U B C 17>E L F 4 A>E F 1 \alpha>18 S$, respectively. The $\mathrm{Ct}$ values from all tested samples under abiotic stress were calculated by RefFinder, and the stability ranking was $U B C 17>U B C 2>\beta T U B>E L F 4 A$. In addition, in biotic-stressed treatment, data from stem and leave tissue was analysed, and $18 S, E L F 4 A, U B C 17$ and $U B C 2$ were ranked as the top four stable genes. The ranking in different tissues under different treatments is shown in Additional file 2: Table S2.

\section{Validation of reference genes}

CPK genes encoding calcium-dependent protein kinases and HSP70 genes encoding heat shock 
protein 70 play an important role in response to environmental stress during plant growth [38-39]. To validate the effectiveness of candidate reference genes, the relative expression levels of PsaHSP70-1 and PsaCPK3 were calculated using selected reference genes under salinity stress and BYDV-GAV infection, and the corresponding transcriptome data is shown in Fig 4. The selected genes were as follows: $18 S$, elf4A and $18 S+U B C 17$ under BYDV-GAV infection in stem and leaf tissue; $U B C 17, U B C 2$ and $\beta T U B+U B C 2$ for salinity stress in stem and leaf tissue; and we also selected $\alpha T U B$ as the least stable gene to evaluate the relative expression levels of $H S P 70$ and CPK-3. Under BYDV-GAV infection, the expression levels of PsaHSP70-1 and PsaCPK3 were higher, and reached their peak after 11 days of virus infection when normalised by $18 S$, elf4A and $18 S+U B C 17$, while the expression of the two genes was much lower when normalised by $\alpha T U B$ (Fig. 4). In the salinity stress group, the expression of PsaHSP70-1 and PsaCPK3 both increased under salinity stress in leaf tissue and the expression peak appeared at $36 \mathrm{~h}$ after the stress. In contrast, the expression level decreased when using $\alpha T U B$ as a reference gene. The expression level of PsaHSP70-1 in stem tissue under salinity stress is also shown in Fig 4, and the transcriptome data was not acquired. According to the normalisation results above, significant differences were observed when using the most stable candidate genes and least stable genes to normalise the PsaHSP70-1 and PsaCPK3, which validated the effectiveness of the most stable reference genes.

\section{Discussion}

P. huashanica, as one of the rare wheat-relative species, contains abundant resistance resources [40]. Along with a growing body of research conducted in P. huashanica, gene expression regulation studies are becoming more important, and quantitative gene expression measurement requires appropriate reference genes. RT-qPCR has become indispensable for the detection and quantification of gene expression because of its numerous advantages and great flexibility [41]. Moreover, validating appropriate reference genes is crucial precondition for quantifying gene expression using RT-qPCR, and hence, the stable reference genes of P. huashanica urgently needed to be validated. Besides, using RT-qPCR technique to investigate the gene expression profiles in P. huashanica not only allows the better understanding of the underlying molecular mechanism in regulation of expression of resistance genes, but it also provides insights into the 
complex regulatory networks involved under different stresses. To obtain reliable and accurate quantification results in RT-qPCR analysis, it is fundamental to select and validate of appropriate reference genes for normalising RT-qPCR data.

RNA-seq has become a powerful tool for high throughput analysis the change of gene transcriptional level under different experimental conditions [42]. This technique has already been widely used in the plant research field for the selection of stably expressed reference genes for RT-qPCR in tomato, Nicotiana benthamiana, grape, soybean, potato and Lycoris aurea $[35,37$, 43-46]. In our study, we took advantage of the RNA-seq dataset generated from BYDV-GAV infected P. huashanica, including inoculated and mock-treated samples. From the dataset, 16 candidate reference genes with low coefficients of variation were selected for further evaluation. This strategy led to the identification of a set of stably expressed genes in P. huashanica.

Four different statistical algorithms (geNorm, NormFinder, Bestkeeper and DeltaCt) and a web-based comprehensive software tool RefFinder were used to evaluate the expression stability of 16 candidate reference genes under various abiotic and biotic stress conditions in P. huashanica. Obvious differences were observed in gene stability rankings generated by these algorithms and tools. For example, under abiotic stress, $18 \mathrm{~S}$ was ranked first by Bestkeeper, whereas it was ranked seventh by RefFinder. Of course, there was also the ranking that could be observed in UBC17 generated by NormFinder, Bestkeeper and DeltaCt at the same time. Differences could also be found under biotic stress; $18 \mathrm{~S}$ was ranked at the top by geNorm, NormFinder, RefFinder and DeltaCt, but it was ranked in the middle position by Bestkeeper. The deviation illustrated above is probably due to the statistical algorithms exploited to calculate stability. The geNorm algorithm procedure is similar to Normfinder software, which uses minimum $\mathrm{Ct}$ values to calculate the $\Delta \mathrm{Ct}$ values and the stability of each candidate reference gene in the total experimental samples [47-48].

Despite these differences, according to the five algorithms, $18 S$ and $U B C 17$ were considered the two most stable reference genes in all the sample sets. Furthermore, our research results are consistent with previous studies, which showed that 18S rRNA was identified as the most stable reference gene in plants under biotic and abiotic stresses, for example, $P$. graminis f. sp. tritici-infected wheat [49], Vigna mungo under drought treatments [50] and Hibiscus cannabinus under excess salinity and drought [51]. $U B C$ is a kind of ubiquitin-conjugating enzyme that targets 
protein for degradation via the proteasome, and is an indispensable component in the life of plants [52]. In addition, UBC was the most stable reference gene identified in Lycoris aurea under $\mathrm{NaCl}$ and cold stresses [46], Pennisetum glaucum under drought, salt, heat, cold and ABA stresses [53] and Corchorus capsularis L. under PEG stress [54]. Moreover, our study results found that $\beta T U B$ and ELF4A performed stable expression in all experimental sets.

In this study, 16 candidate reference genes were selected from large-scale transcriptome data (unpublished) and previous studies serving as the source of the reference gene selection for evaluation of expression stability. The expression levels and stabilities of 16 candidate reference genes were analysed in various tissues submitted to different stress treatments as well as at different development periods in P. huashanica. To the best of our knowledge, this is the first report on the identification and validation of suitable reference genes for normalising RT-qPCR analysis in P. huashanica under various experimental conditions.

\section{Conclusions}

In this study, with three computer algorithms, geNorm, BestKeeper and NormFinder, and a comprehensive ranking tool RefFinder, we identified a series of stably expressed RG sets (including $18 \mathrm{~S}+\mathrm{UBC} 17$ under biotic stress and $\beta \mathrm{TUB}+\mathrm{UBC} 2$ under abiotic stress) from 16 candidate reference genes from different tissue samples and different conditions at different time points in P. huashanica. A further expression analysis of PsaCPK3 and PsaHSP70-3 in leaves and stems subjected to both abiotic and biotic stress confirmed the suitability of the novel reference gene set. The results provide valuable information for more precise RT-qPCR data normalisation and further gene expression studies in P. huashanica.

\section{Materials and methods}

\section{Plant Materials and Stress Treatments}

The P. huashanica plants used in this study were grown in a greenhouse. For drought and salinity treatments, the plants were supplemented with Hoagland solution containing $15 \% \mathrm{PEG}_{6000}$ and $200 \mathrm{mM} \mathrm{NaCl}$, respectively, for $0,12,36$ and $72 \mathrm{~h}$. For cold and hot treatments, the plants were exposed to low and high temperature in an incubator at $4{ }^{\circ} \mathrm{C}$ and $40^{\circ} \mathrm{C}$, respectively, for $0,6,12$ and $24 \mathrm{~h}$. For hormone treatments, plants were sprayed with $200 \mathrm{mM} \mathrm{ABA}$ and IAA solutions for 
0, 12, 36 and $72 \mathrm{~h}$. For virus treatments, leaves were inoculated with viruliferous aphids carrying BYDV-GAV, control plants (mock-infected) were inoculated with non-viruliferous aphids, and samples were collected at $0,3,7$ and $14 \mathrm{~d}$, consisting of five aphids per leaf [55]. For fungal treatments, leaves inoculated with Pst virulent isolate CYR32 [56] were collected at 0, 3, 7, and 14 d. All treatments were performed with three biological replications, immediately frozen in liquid nitrogen and stored at $-80^{\circ} \mathrm{C}$ for RNA extraction.

\section{Total RNA Isolation and cDNA Synthesis}

Total RNA was isolated with a Biospin Plant Total RNA Extract Kit, which purifies all sizes of total RNA, and genomic DNA was removed by DNase I (RNase free) (bioer, Hangzhou, China) according to the manufacturer's instructions with some modifications. The integrity of total RNA was assessed by $1.5 \%$ agarose-gel electrophoresis, and the quantity and quality of RNA was further measured by NanoDrop 2000 spectrophotometer (Thermo Fisher Scientific, Delaware, USA). Only RNA samples with an OD260/280 value between 1.8 and 2.2 were used for cDNA synthesis. A total of $1.0 \mu \mathrm{g}$ RNA was performed into cDNA synthesis in a $20-\mu 1$ reaction mixture using a PrimeScript ${ }^{\mathrm{TM}}$ RT Reagent Kit (Takara, Dalian, China) according to the manufacturer's instructions. The cDNA was diluted 4-fold with nuclease-free water to $100 \mu \mathrm{l}$ for RT-qPCR.

\section{Reference Gene Selection and Primer Design}

Taking advantage of newly generated RNA-seq data that P. huashanica leaves challenged with BYDV-GAV, we chose those with high expression (mostly, RPKM > 10) and ranked them based on their coefficient of variation (CV) (Additional file 2: Table S2). Finally, 16 genes were selected as the candidate reference genes. The corresponding reference genes coding sequences were extracted based on the transcriptome sequencing database built by our lab (unpublished). The primers were designed for RT-qPCR using the Primer 3 Plus program (www.primer3plus.com/cgi-bin/dev/primer3plus.cgi) according to the following parameters: the amplicon product size was set as $80-150 \mathrm{bp}$, primer length was $18-24 \mathrm{bp}$, melting temperature (Tm) was $55-62^{\circ} \mathrm{C}$ and $\mathrm{GC}$ content was $40-70 \%$. Then, the amplification specificity of primers was confirmed by RT-PCR with a 1.2\% agarose-gel electrophoresis.

\section{Real-Time Quantitative PCR Analysis}

RT-qPCR analysis was performed using UltraSYBR Mixture (cwbiotech, Jiangsu, China), and the reactions were conducted in a final volume of $25 \mu 1$ containing $12.5 \mu 1$ of 2x UltraSYBR Mixture, 
$0.2 \mathrm{uM}$ of each primer, $1.0 \mu \mathrm{l}$ of diluted cDNA and nuclease-free water. A Bio-Rad CFX96 system (Bio-Rad, Hercules, CA, USA) was used to perform RT-qPCR reaction with the following conditions: initial denaturation at $95^{\circ} \mathrm{C}$ for $10 \mathrm{~min}$, followed by 40 cycles of $95^{\circ} \mathrm{C}$ for $15 \mathrm{~s}$ and $60^{\circ} \mathrm{C}$ for $1 \mathrm{~min}$, and a melting-curve program was generated by the instrument. Each real-time PCR reaction was performed with three technical and biological replicates.

\section{Data Analysis}

Expression levels of the 16 reference genes in all samples were determined by their cycle threshold values $(\mathrm{Ct})$. The PCR amplification efficiency of each gene was evaluated using a standard curve generated by RT-qPCR using a fourfold dilution series of cDNA templates $(1,1 / 10$, $1 / 100,1 / 1000,1 / 10000)$. The correlation coefficients $\left(R^{2}\right)$ and slope values were obtained from standard curves. The PCR efficiency (E) was calculated using the slope value with the formula ( $E$ $\left.=\left(10^{(-1 / \text { slope })}-1\right) \times 100 \%\right)[57]$.

Five different statistical algorithms (geNorm [58], NormFinder [59], Bestkeeper [60], Delta CT method [61] and RefFinder [62]) were used to calculate the expression stability of candidate reference genes. $\mathrm{Ct}$ values were converted to relative quantities according to the formula $\left(2^{-\Delta \mathrm{Ct}}\right)$ for the geNorm and NormFinder analysis. RefFinder, a web-based tool, integrates the four computational programs (geNorm, NormFinder, BestKeeper, and the Delta CT method) to generate a comprehensive ranking of candidate reference genes according to the total experimental treatments.

\section{Validation of Reference Genes}

To validate the reliability of selected reference genes, the top two stable reference genes, an optimum reference gene combination and the most unstable reference gene were used to normalise the relative expression levels of PsaHSP70-1 and PsaCPK3 in biotic and abiotic experimental conditions. The relative expression levels at different time points were calculated using the $2^{-\Delta \Delta C t}$ method [63]. The qPCR primer pairs designed by Primer 3 for PsaHSP70-3 were 5'-AAGAAGgGCGGTGAGAAGAA-3' and 5'-CCCTCCTCAGCTTTCCAAGA-3', and for PsaCPK3, the primer pairs were 5'-GCGATGAGGCGACAATCAAA-3' and 5'GTCACCTGTCTCAATGCGTC-3’. 


\begin{abstract}
Abbreviations
$18 S$ rRNA: $18 \mathrm{~S}$ ribosomal RNA; EF1- $\alpha$ : eukaryotic elongation factor 1 alpha; UBC2: ubiquitin-conjugating enzyme E2-2; UBC17: ubiquitin-conjugating enzyme E2-17; $\alpha-T U B 2 A$ : alpha tubulin-2A; $\beta$-TUB3: beta tubulin 3; ADF4: Actin-depolymerising factor 4; ACTIN: actin; GAPDH: Glyceraldehyde-3-phosphate dehydrogenase; 60SARP: 60S acidic ribosomal protein; $U B Q$ : polyubiquitin; SamDC: S-Adenosylmethionine decarboxylase; EIF4A: eukaryotic initiation factor 4A; ARF: ADP-ribosylation factor; HIS1: histone H1; HIS2B: histone H2B; RT-qPCR: Quantitative real-time polymerase chain reaction
\end{abstract}

\title{
Ethics approval and consent to participate
}

Not applicable.

\section{Consent for publication}

Not applicable

\section{Availability of data and materials}

The datasets supporting the conclusions of this article are included within the article and its additional fles.

\section{Competing interests}

The authors declare that they have no competing interests.

\section{Funding}

This research was supported by grants from the National Transgenic Science and Technology Program (2016ZX08010-002) and the 111 project from the Education Ministry of China (No.B07049).

\section{Authors' contributions}

CS, JL and YW designed the research. CS, JL, CW and XZ performed the experiments. CS, JL and YW contributed to data analysis and helped to draft the manuscript. All authors read and 
approved the final manuscript.

\section{Acknowledgements}

Not applicable

\section{Additional files}

Additional file 1: Fig. S1. Melt curve analysis of the selected 16 candidate reference genes.

Table S1. The CT values of the total 16 reference genes under different conditions.

Additional file 2: Table S2. Expression stability ranking under different tissues and different stresses.

Table S3. Selection of candidate reference genes from RNA-seq data based on RPKM expression and coefficient of variation (CV).

Table 1. The characteristics of candidate reference genes and corresponding primers

\begin{tabular}{|c|c|c|c|c|c|c|c|}
\hline gene symbol & gene name & gene ID & Forward primer sequence $\left(5^{\prime}-3^{\prime}\right)$ & Reverse primer sequence $\left(5^{\prime}-3^{\prime}\right)$ & Size(bp) & $\mathbf{E}(\%)$ & $\mathbf{R}^{2}$ \\
\hline $18 \mathrm{~S}$ & $18 \mathrm{~S}$ rRNA & Isoform_40207 & GTGAAGACGGTGAGATGTGC & \begin{tabular}{|l} 
TTCTGCCTCTTGTTCGACCT \\
\end{tabular} & 115 & 95.71008 & 0.9987 \\
\hline EF1 $\alpha$ & eukaryotic elongation factor 1 alpha & Isoform_18504 & TTGAGATGCACCACGAGTCT & CAACAAACCCACGCTTGAGA & 159 & 98.68284 & 0.9978 \\
\hline UBC2 & ubiquitin-conjugating enzyme E2-2 & Isoform_54942 & TGCAAGGAAGAGGCTGATGA & TTGAACGTACCACCATCCCA & 150 & 97.63233 & 0.9959 \\
\hline UBC17 & ubiquitin-conjugating enzyme E2-17 & Isoform_57085 & TCTGCTTTCAATCTGCTCGC & TGTCGTCTCGTACTTGGACC & 103 : & 90.93045 & 0.9945 \\
\hline$\alpha$ TUB & alpha tubulin-2A & Isoform_12228 & TTTCCTCCTATGCCCCAGTG & AGACAGCAGGCCATGTACTT & 126 & 83.99646 & 0.9935 \\
\hline$\beta$ TUB & beta tubulin 3 & Isoform_10167 & TGACATTCTCGGTGTTCCCA & GAGCCTCGTTGTCAAGAACC & 126 & 100.7325 & 0.9983 \\
\hline ADF4 & Actin-depolymerizing factor 4 & Isoform_50056 & GCGGTGTTTGACTTCGACTT & CGTCCAGGGTCCTCTTGAAT & 145 & 94.8177 & 0.997 \\
\hline actin & actin & Isoform_17349 & TGGTATGGAAGCTGCTGGAA & TCAGCAATACCCGGGAACAT & 132 & 87.62201 & 0.991 \\
\hline GAPDH & Glyceraldehyde-3-phosphate dehydrogenase & Isoform_15392 & CCTGCTCAAGTACGACTCGA & GACGACCTGGATGTTCTTGC & 100 & 89.1111 & 0.9965 \\
\hline 60SRP & 60S acidic ribosomal protein & Isoform_ 76159 & CTTCTGAGAAGATCGCGACG & TCATCCACGCTCCTCTTCTC & 103 & 75.22157 & 0.9945 \\
\hline ubi & polyubiquitin & Isoform_61698 & ACGAACAAATCCGCAACCAA & TCAGACGACTCCACCTCAAG & 137 & 88.70282 & 0.9969 \\
\hline SamDC & S-Adenosylmethionine decarboxylase & Isoform_ 38601 & ATGTGCATGACTGGTCTGGA & CCACACGGCTCGAAATCAAA & 158 & 95.62585 & 0.9977 \\
\hline elf4A & eukaryotic initiation factor $4 \mathrm{~A}$ & Isoform_12584 & CCAGCAGGTCTCTCTTGTCA & ACAAAGTTGATCGCCACACC & 114 & 91.40804 & 0.9965 \\
\hline ARF & ADP-ribosylation factor & Isoform_ 38525 & CCAGAACACTCAGGGCCTTA & GCAGCTCATCCTCATTCAGC & 104 & 97.06593 & 0.9979 \\
\hline HIS1 & histone $\mathrm{HI}$ & Isoform_51494 & TACATCGAGGAGAAGCACGG & GACCTTGACGAGCTTACCCT & 102 & 95.00621 & 0.9993 \\
\hline HIS4 & histone $\mathrm{H} 2 \mathrm{~B}$ & Isoform 63718 & GGCAGGAAGAAGAACAAGAAGAG & GAAGATGTCGTTGATGAAGGAGTT & 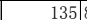 & 84.31553 & 0.9994 \\
\hline
\end{tabular}

Table 2. Expression stability ranking under abiotic and biotic stresses 


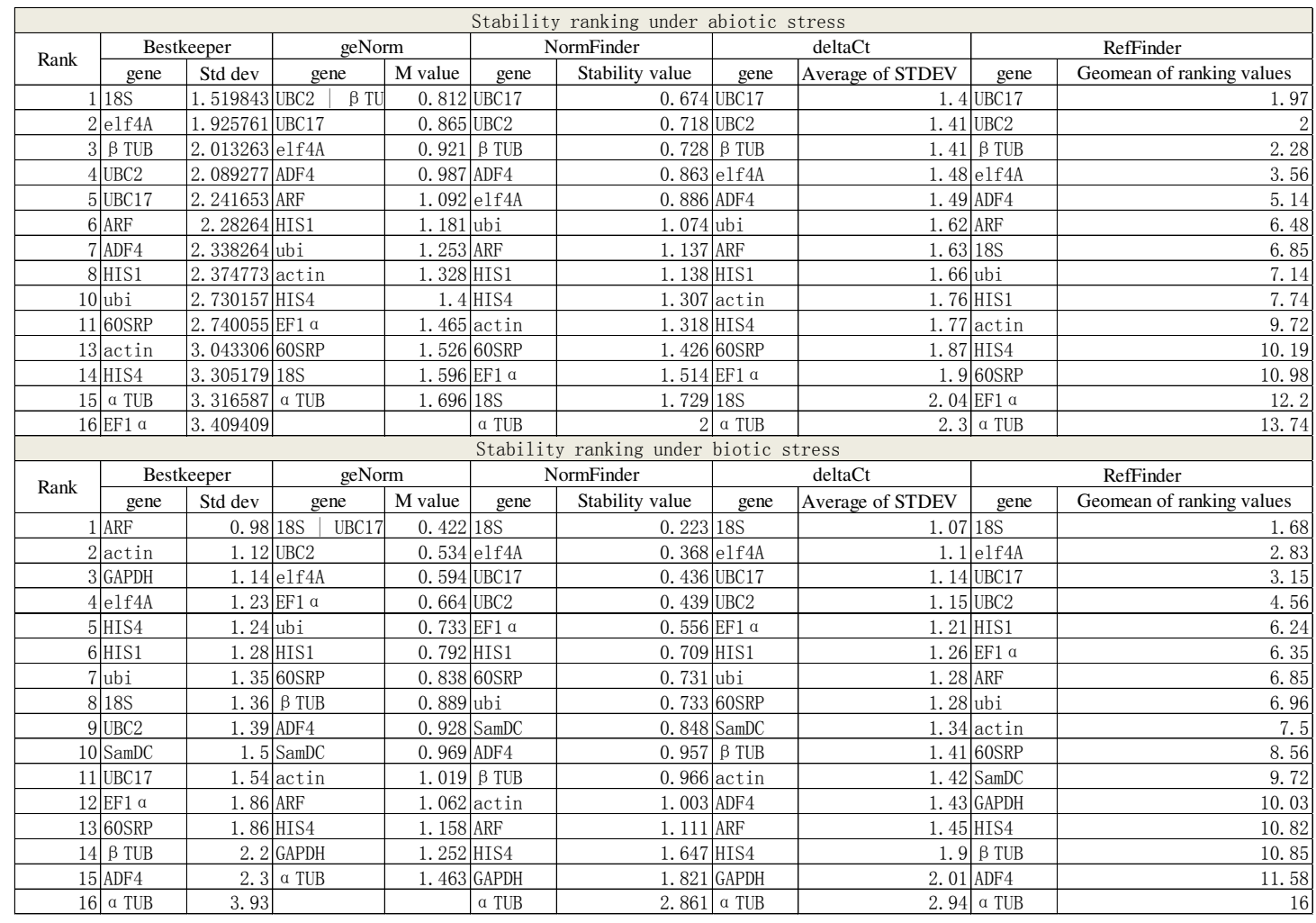

Table 3. Expression stability ranking under different abiotic stresses 


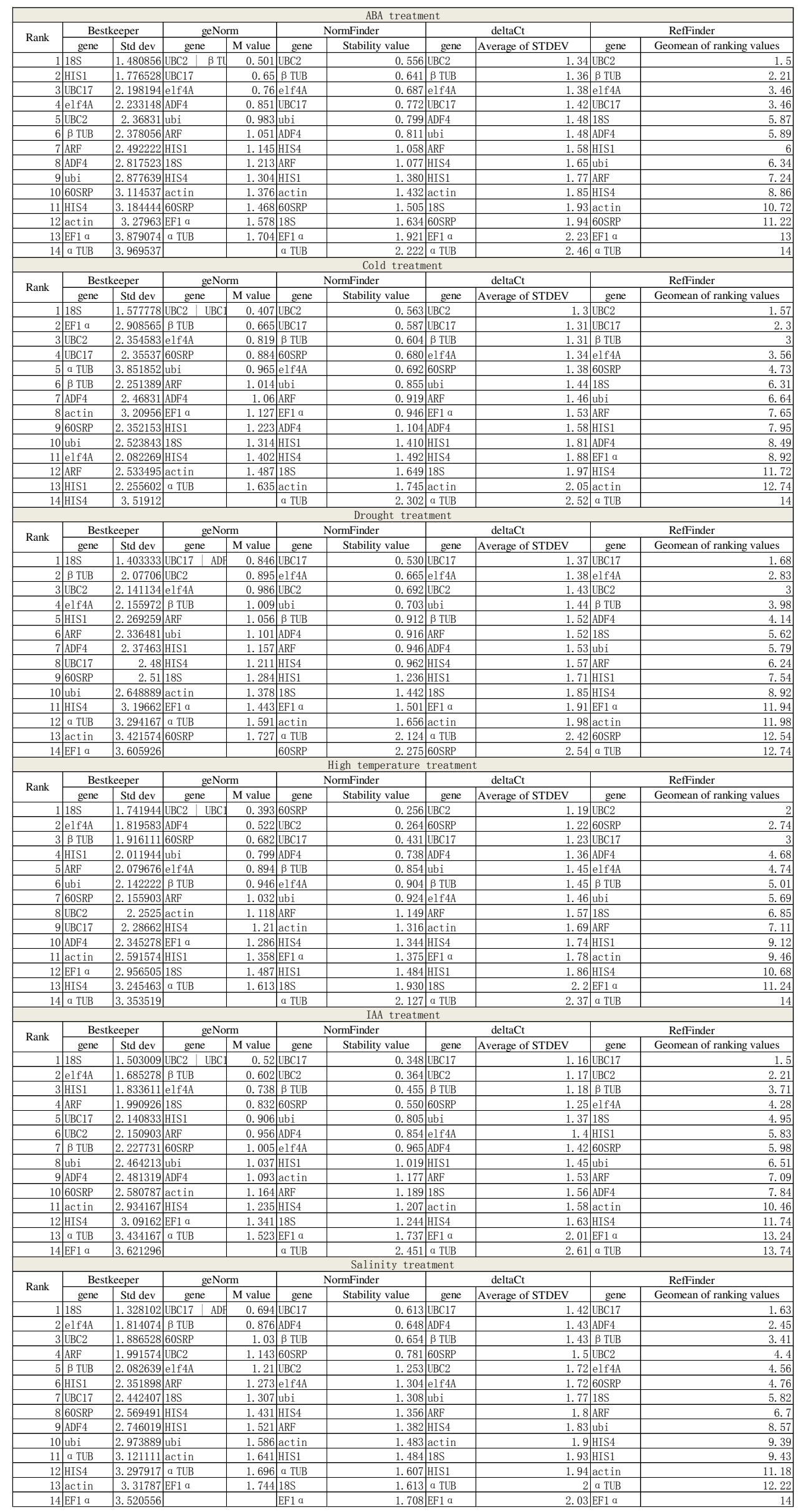


Fig. 1. The PCR amplifcation specifcities of candidate reference genes detected by agarose gel electrophoresis. M represents the DNA size marker.

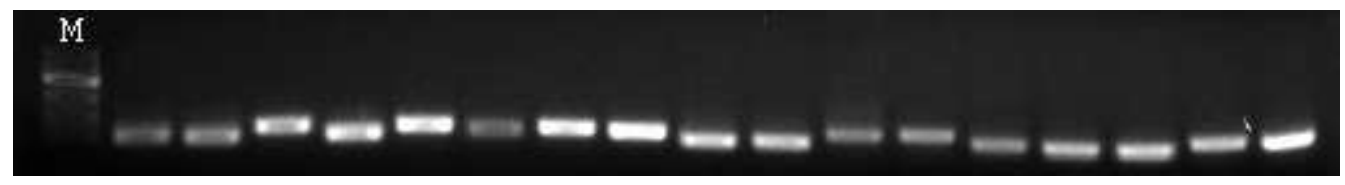

Fig. 2. Distribution of CT values of 16 candidate genes in all samples. Boxplot graph showing maximum,minimum values, medians and 25/75 percentiles.

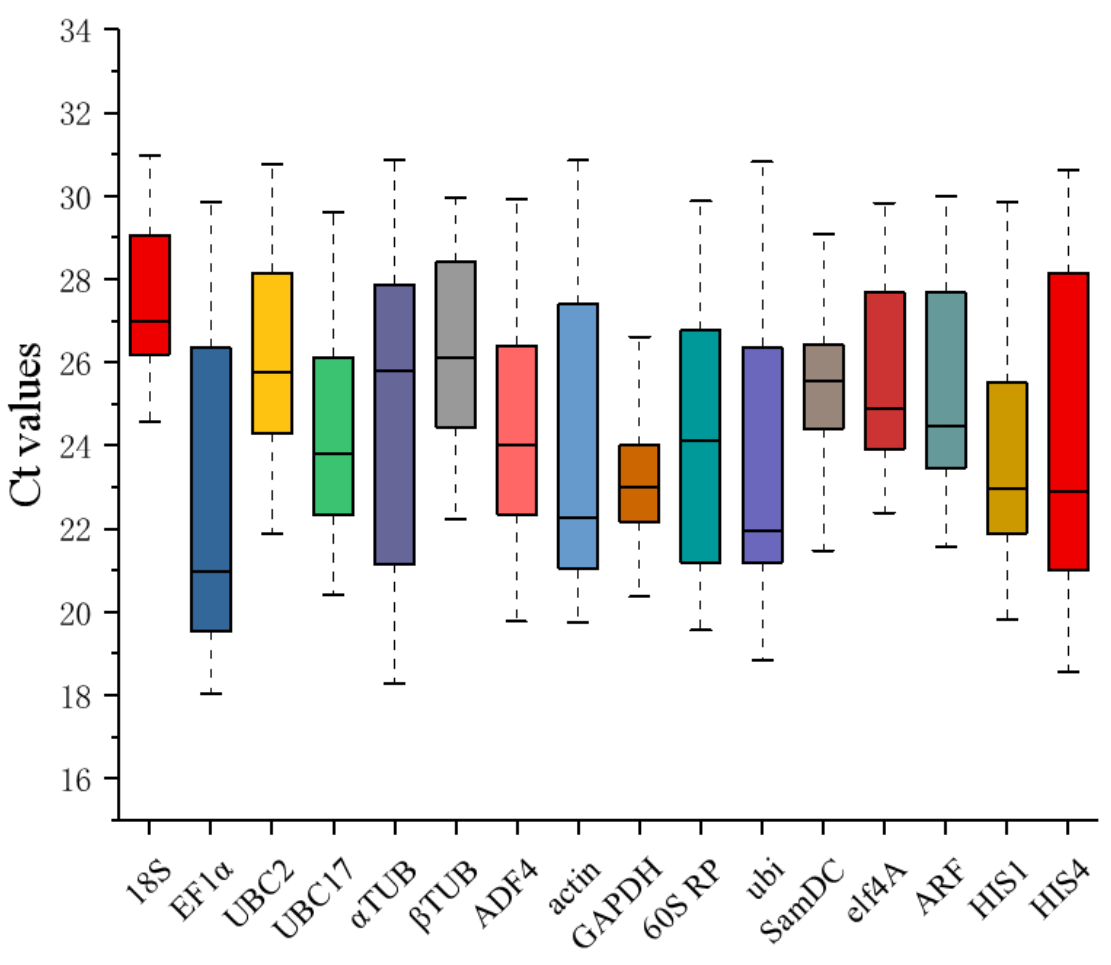

Fig. 3. (a) Pairwise variation (V) analysis of 14 candidate genes under abiotic stress in different tissues; (b) Pairwise variation (V) analysis of 14 candidate genes under different abiotic stress; (c) Pairwise variation (V) analysis of 14 candidate genes in root tissue under biotic stress; (d) Pairwise variation (V) analysis of 14 candidate genes in stem tissue under abiotic stress; (e) Pairwise variation (V) analysis of 14 candidate genes in leave tissue under abiotic stress; (f) Pairwise variation (V) analysis of 14 candidate genes under biotic stress; (g) Pairwise variation (V) analysis of 14 candidate genes under abiotic stress. 

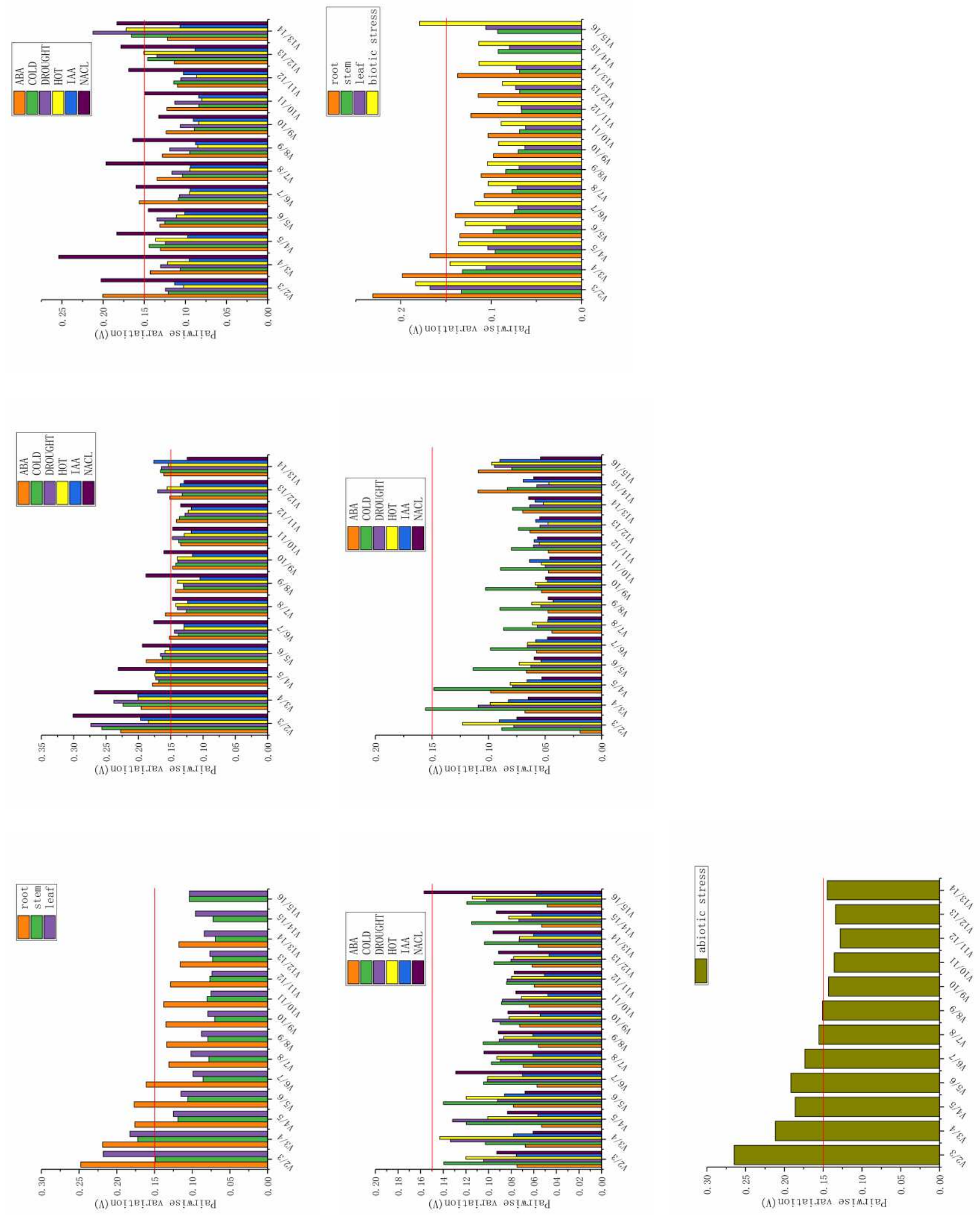
Fig. 4. (a) Relative expression level of $P s a C P K 3$ under BYDV-GAV infection in leave tissue and corresponding transcriptome data RNA-seq; (b) relative expression level of PsaHSP70-3 under BYDV-GAV infection in leave tissue; (c) relative expression level of PsaHSP70-3 under salinity stress in leave tissue;(d) relative expression level of PsaCPK3 under salinity stress in leave tissue;(e) relative expression level of PsaHSP70-3 under salinity stress in stem tissue.
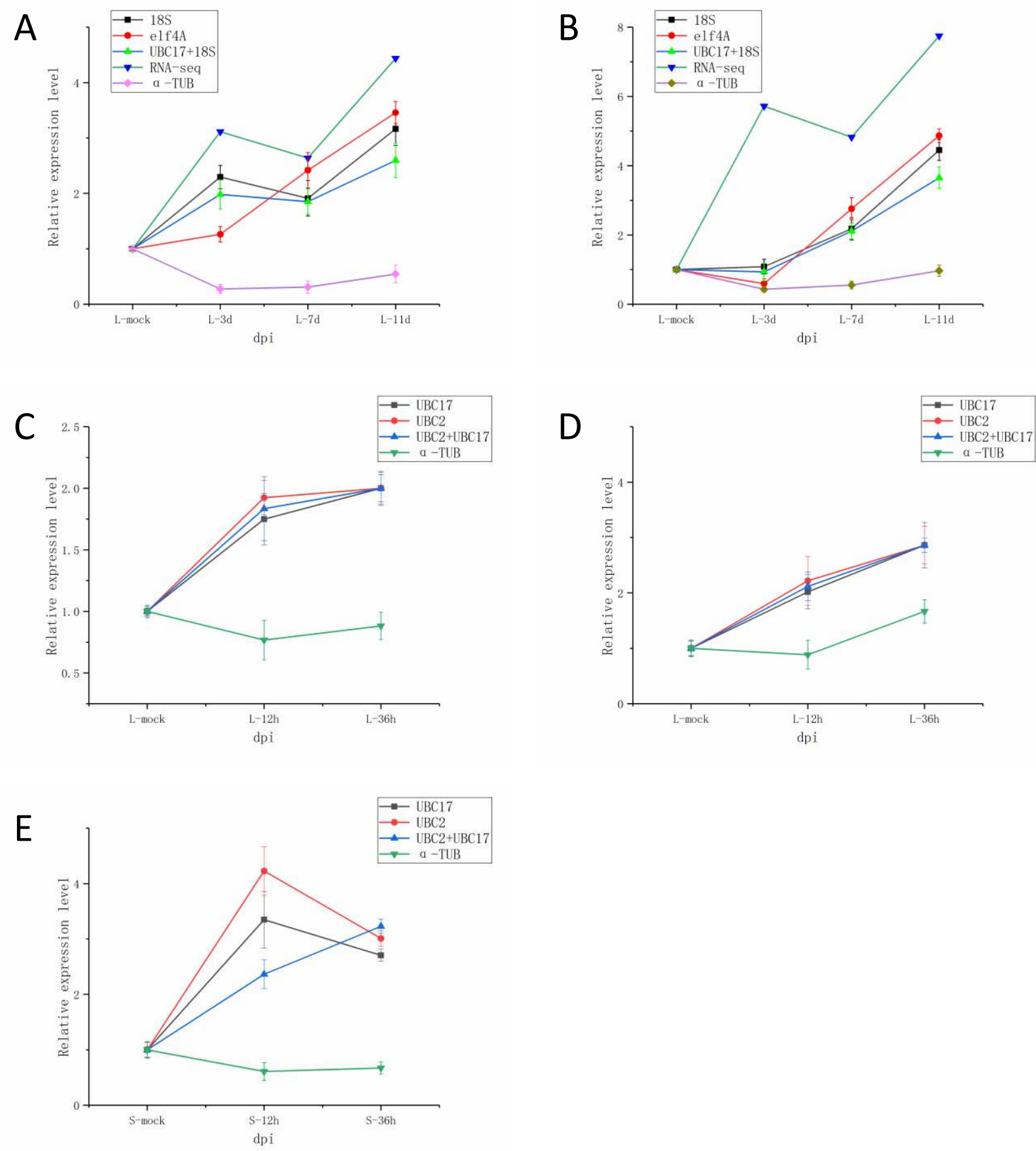


\section{References}

1. Du YN, Chen XH, Zhao JX, Liu SH, Yang QH, Zhou B, Wu J, Liu PL. Analysis of drought resistance of Triticum aestivum -Psathyrostachys derivatives at the germination and seedling stages. Journal of Triticeae Crops. 2010;30(4):670-75.

2. He X, Chen Z, Wang J, Li W, Zhao J, Wu J, Wang Z, Chen X. A sucrose: fructan-6fructosyltransferase (6-SFT) gene from Psathyrostachys huashanica confers abiotic stress tolerance in tobacco. Gene. 2015;570(2):239-47.

3. Kang HY, Zhang ZJ, Xu LL, Qi WL, Tang Y, Wang H, Zhu W, Li DY, Zeng J, Wang Y, et al. Characterization of wheat-Psathyrostachys huashanica small segment translocation line with enhanced kernels per spike and stripe rust resistance. Genome. 2016;59(4):221-29.

4. Song S, Tao Y, Zhang H, Wu Y. Psathyrostachys huashanica, a potential resource for resistance to Barley yellow dwarf virus-GAV. European Journal of Plant Pathology. 2013;137(2):217-21.

5. Fu J, Wang M, Zhao J, Chen S, Hou W, Yang Q. Studies on cytogenetics and utilization of wheat-Psathyrostachys huashanica medium material H8911 with resistance to wheat take-all fungus. Acta Botanica Boreali-occidentalia Sinica. 2003;23(12):2157-62.

6. Hang Y, Jin Y, Lu BR. Genetic diversity of the endangered species Psathyrostachys huashanica in China and its strategic conservation. Journal of Fudan University. Natural Science. 2004;43(2):260-66.

7. Wanli D, Jing W, Yuhui P, Yanli L, Xinhong C, Jixin Z, et al. Isolation and characterization of a Psathyrostachys huashanica keng 6ns chromosome addition in common wheat. PLoS ONE. 2013;8(1):e53921-.

8. Du W, Wang J, Lu M, Sun S, Chen X, Zhao J, et al. Characterization of a wheat-Psathyrostachys, huashanica, keng 4ns disomic addition line for enhanced tiller numbers and stripe rust resistance. Planta. 2014;239(1):97-105.

9. Gachon C, Mingam A, Charrier B. Real-time PCR: what relevance to plant studies?. Journal of Experimental Botany. 2004;55(402):1445-54.

10. Bustin, S. Quantification of mRNA using real-time reverse transcription PCR (RT-PCR): trends and problems. Journal of Molecular Endocrinology. 2002;29(1):23-39.

11. Bustin SA, Benes V, Nolan T, Pfaffl MW. Review; Quantitative real-time RT-PCR-a perspective. Journal of Molecular Endocrinology. 2005;34(3):597-601. 
12. Nolan T, Hands RE, Bustin SA. Quantification of mRNA using real-time RT-PCR. Nature Protocols. 2006;1(3):1559-82.

13. Andersen CL, Jensen JL, Ørntoft TF. Normalization of real-time quantitative reverse transcription-PCR data: a model-based variance estimation approach to identify genes suited for normalization, applied to bladder and colon cancer data sets. Cancer Research. 2004;64(15):5245-50.

14. Gutierrez L, et al. The lack of a systematic validation of reference genes: a serious pitfall undervalued in reverse transcription-polymerase chain reaction (RT-PCR) analysis in plants. Plant Biotechnology Journal. 2008;6(6):609-18.

15. Xiao X, Ma J, Wang J, Wu X, Li P, Yao Y. Validation of suitable reference genes for gene expression analysis in the halophyte Salicornia europaea by real-time quantitative PCR. Frontiers in Plant Science. 2014,5(788):788.

16. Jain M, Nijhawan A, Tyagi AK, Khurana JP. Validation of housekeeping genes as internal control for studying gene expression in rice by quantitative real-time PCR. Biochemical and Biophysical Research Communications. 2006;345(2):0-651.

17. Saraiva, Kátia DC, Dirce FDM, Morais VD, Vasconcelos IM, Costa JH. Selection of suitable soybean EF1 $\alpha$ genes as internal controls for real-time PCR analyses of tissues during plant development and under stress conditions. Plant Cell Reports. 2014;33(9):1453-65.

18. Nicot N, Hausman JF, Hoffmann L, Evers D. Housekeeping gene selection for real-time RT-PCR normalization in potato during biotic and abiotic stress. Journal of Experimental Botany. 2005;56(421):2907-14.

19. Wang Z, Chen Y, Fang HD, Shi HF, Chen KP, Zhang ZY, Tan XL. Selection of reference genes for quantitative reverse-transcription polymerase chain reaction normalization in Brassica napus under various stress conditions. Molecular Genetics and Genomics. 2014;289(5):1023-35.

20. Kim BR, Nam HY, Kim SU, Kim SI, Chang YJ. Normalization of reverse transcription quantitative-PCR with housekeeping genes in rice. Biotechnology Letters. 2003;25(21):1869-72.

21. Yan J, Yuan F, Long G, Qin L, Deng Z. Selection of reference genes for quantitative real-time RT-PCR analysis in citrus. Molecular Biology Reports. 2012;39(2):1831-38.

22. Lilly ST, Drummond RSM, Pearson MN, Macdiarmid RM. Identification and validation of reference genes for normalization of transcripts from virus-infected Arabidopsis thaliana. 
Molecular Plant-Microbe Interactions. 2011;24(3):294-304.

23. Bevitori R, Oliveira MB, M F, Grossi-de-Sá, Lanna AC, Silveira RDD, Petrofeza S. Selection of optimized candidate reference genes for qRT-PCR normalization in rice (Oryza sativa L.) during Magnaporthe oryzae infection and drought. Genetics \& Molecular Research Gmr. 2014;13(4):9795-805.

24. Enrico P, Paolacci AR, Tanzarella OA, Mario C. Identification and validation of reference genes for quantitative RT-PCR normalization in wheat. BMC Molecular Biology. 2009;10(1):11.

25. Hua W, Zhu J, Shang Y, Wang J, Jia Q, Yang J. Identification of suitable reference genes for barley gene expression under abiotic stresses and hormonal treatments. Plant Molecular Biology Reporter. 2015;33(4):1002-12.

26. Meizhen W, Shanfa L. Validation of suitable reference genes for quantitative gene expression analysis in Panax ginseng. Frontiers in Plant Science. 2016; doi:10.3389/fpls.2015.01259.

27. Hu R, Fan C, Li H, Zhang Q, Fu YF. Evaluation of putative reference genes for gene expression normalization in soybean by quantitative real-time RT-PCR. BMC Molecular Biology. 2009;10(1):93.

28. Qiusheng K, Lingyun G, Lei C, Yue L, Hameed S, Yuan H, et al. Assessment of suitable reference genes for quantitative gene expression studies in melon fruits. Frontiers in Plant Science. 2016; doi:10.3389/fpls.2016.01178.

29. Ferradás Y, Rey L, Martínez Ó Rey M, González MV. Identification and validation of reference genes for accurate normalization of real-time quantitative PCR data in kiwifruit. Plant Physiology and Biochemistry. 2016;102:27-36.

30. Xu Y, Li H, Li X, Lin J, Wang Z, Yang Q, et al. Systematic selection and validation of appropriate reference genes for gene expression studies by quantitative real-time PCR in pear. Acta Physiologiae Plantarum. 2015;37(2):40.

31. Fuentes A, Ortiz J, Saavedra N, Salazar LA, Meneses C, Arriagada C. Reference gene selection for quantitative real-time PCR in Solanum lycopersicum L. inoculated with the mycorrhizal fungus Rhizophagus irregularis. Plant Physiology and Biochemistry. 2016;101:124-31.

32. Meizhen H, Wenbin H, Zhiqiang X, Xincheng Z, Wenquan W. Validation of reference genes for relative quantitative gene expression studies in cassava (Manihot esculenta Crantz) by using 
quantitative real-time PCR. Frontiers in Plant Science. 2016; doi:10.3389/fpls.2016.00680.

33. Buermans HPJ, Den Dunnen JT. Next generation sequencing technology: Advances and applications. Biochimica et Biophysica Acta (BBA)-Molecular Basis of Disease. 2014;1842(10):1932-41.

34. Wang L, Li P, Brutnell TP. Exploring plant transcriptome using ultra high-throughput sequencing. Briefings in Functional Genomics. 2010;9(2):118-28.

35. Pombo MA, Zheng Y, Fei Z, Martin GB, Rosli HG. Use of RNA-seq data to identify and validate RT-qPCR reference genes for studying the tomato-Pseudomonas pathosystem. Scientific Reports. 2017;7:44905.

36. Rosli H, et al. Transcriptomics-based screen for genes induced by flagellin and repressed by pathogen effectors identifies a cell wall-associated kinase involved in plant immunity. Genome biology. 2013;14(12):R139.

37. Pombo MA, Ramos RN, Zheng Y, et al. Transcriptome-based identification and validation of reference genes for plant-bacteria interaction studies using Nicotiana benthamiana. Scientific Reports. 2019;9:1632.

38. Boorstein WR, Ziegelhoffer T, Craig EA. Molecular evolution of the HSP70 multigene family. Journal of Molecular Evolution. 1994;38(1):1-17.

39. Ludwig AA, Romeis T, Jones JDG. CDPK-mediated signalling pathways: Specificity and cross-talk. Journal of Experimental Botany. 2004;55(395);181-88.

40. Chen SY, Zhang AJ, Fu J. The Hybridization Between Triticum aestivum and Psathyrostachys huashanica. Acta genetica sinica. 1991;18(6):508-12.

41. Derveaux S, Vandesompele J, Hellemans J. How to do successful gene expression analysis using real-time PCR. Methods. 2010;50(4):227-30.

42. Wang Z, Gerstein M, Snyder M. RNA-Seq: a revolutionary tool for transcriptomics. Nature Reviews Genetics. 2010;10(1):57-63.

43. González-Agüero M, et al. Identification of two putative reference genes from grapevine suitable for gene expression analysis in berry and related tissues derived from RNA-Seq data. BMC Genomics. 2013;14(1):878-78.

44. Yim AK-Y, et al. Using RNA-seq data to evaluate reference genes suitable for gene expression studies in soybean. PLoS ONE. 2015; doi:10.1371/journal.pone.0136343. 
45. Mariot RF, et al. Selection of reference genes for transcriptional analysis of edible tubers of potato (Solanum tuberosum L.). PLoS One. 2015;10(4):e0120854.

46. Ma R, Xu S, Zhao Y, Xia B, Wang R. Selection and validation of appropriate reference genes for quantitative real-time PCR analysis of gene expression in Lycoris aurea. Frontiers in Plant Science. 2016;7:536.

47. Vandesompele J, De Prete K, Pattyn F, Poppe B, Van Roy N, De Paepe A, Speleman F. Accurate normalization of real-time quantitative RT-PCR data by geometric averaging of multiple internal control genes. Genome Biology. 2002;3(7):research0034.1.

48. Andersen CL, Jensen JL, Ørntoft TF. Normalization of real-time quantitative reverse transcription-PCR data: a model-based variance estimation approach to identify genes suited for normalization, applied to bladder and colon cancer data sets. Cancer Research. 2004;64(15):5245-50.

49. Scholtz JJ, Visser B. Reference gene selection for qPCR gene expression analysis of rust-infected wheat. Physiological and molecular plant pathology. 2013;81:22-25.

50. Kundu A, Patel A, Pal A. Defining reference genes for qPCR normalization to study biotic and abiotic stress responses in Vigna mungo. Plant cell reports. 2013;32(10):1647-58.

51. Niu X, Qi J, Chen M, et al. Reference genes selection for transcript normalization in kenaf (Hibiscus cannabinus L.) under salinity and drought stress. PeerJ. 2015;3(3):e1347.

52. Criqui, M C. Molecular characterization of plant ubiquitin-conjugating enzymes belonging to the UbcP4/E2-C/UBCx/UbcH10 gene family. Plant Physiology. 2002;130(3):1230-40.

53. Shivhare R, Lata C. Selection of suitable reference genes for assessing gene expression in pearl millet under different abiotic stresses and their combinations. Scientific Reports. 2016;6:23036.

54. Niu X, Qi J, Zhang G, et al. Selection of reliable reference genes for quantitative real-time PCR gene expression analysis in Jute (Corchorus capsularis) under stress treatments. Frontiers in Plant Science. 2015;6:848 .

55. Tao Y, Nadege SW, Huang C, Zhang P, Wu Y. Brachypodium distachyon is a suitable host plant for study of Barley yellow dwarf virus. Virus Genes. 2016;52(2):1-4.

56. Kang ZS, Huang LL, Buchenauer H. Ultrastructural changes and localization of lignin and callose in compatible and incompatible interactions between wheat and Puccinia striiformis. 
Journal of Plant Diseases and Protection. 2002;109(1):25-37.

57. Radonić A, Thulke S, Mackay IM, et al. Guideline to reference gene selection for quantitative real-time PCR. Biochemical and Biophysical Research Communications. 2004;313(4):0-862.

58. Vandesompele J, De Preter K, Pattyn F, et al. Accurate normalization of real-time quantitative RT-PCR data by geometric averaging of multiple internal control genes. Genome Biology. 2002;3(7): research0034.1-0034.11.

59. Andersen CL, Jensen JL, Ørntoft TF. Normalization of real-time quantitative reverse transcription-PCR data: a model-based variance estimation approach to identify genes suited for normalization, applied to bladder and colon cancer data sets. Cancer Research. 2004;64(15):5245-50.

60. Pfaffl MW, Tichopad A, Prgomet C, Neuvians TP. Determination of stable housekeeping genes, differentially regulated target genes and sample integrity: BestKeeper-Excel-Based tool using pair-wise correlations. Biotechnology Letters. 2004;26(6):509-15.

61. Schmittgen TD, Livak KJ. Analyzing real-time PCR data by the comparative CT method. Nature Protocols. 2008;3(6):1101-08.

62. Chen D, Pan X, Xiao P, et al. Evaluation and identification of reliable reference genes for pharmacogenomics, toxicogenomics, and small RNA expression analysis. Journal of Cellular Physiology. 2011;226(10):2469-77.

63. Livak K, Schmittgen T. Analysis of relative gene expression data using real-time quantitative PCR and the 2- $\Delta \Delta C T$ method. Methods. 2000;25(4):402-08. 
Figures

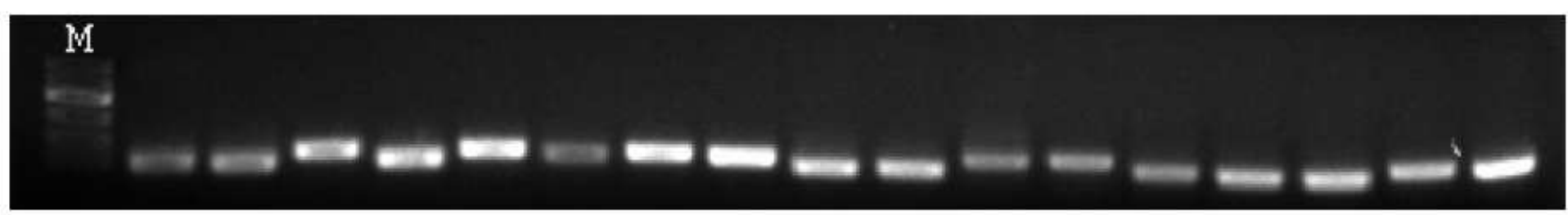

Figure 1

Fig. 1. The PCR amplifcation specifcities of candidate reference genes detected by agarose gel electrophoresis. M represents the DNA size marker.

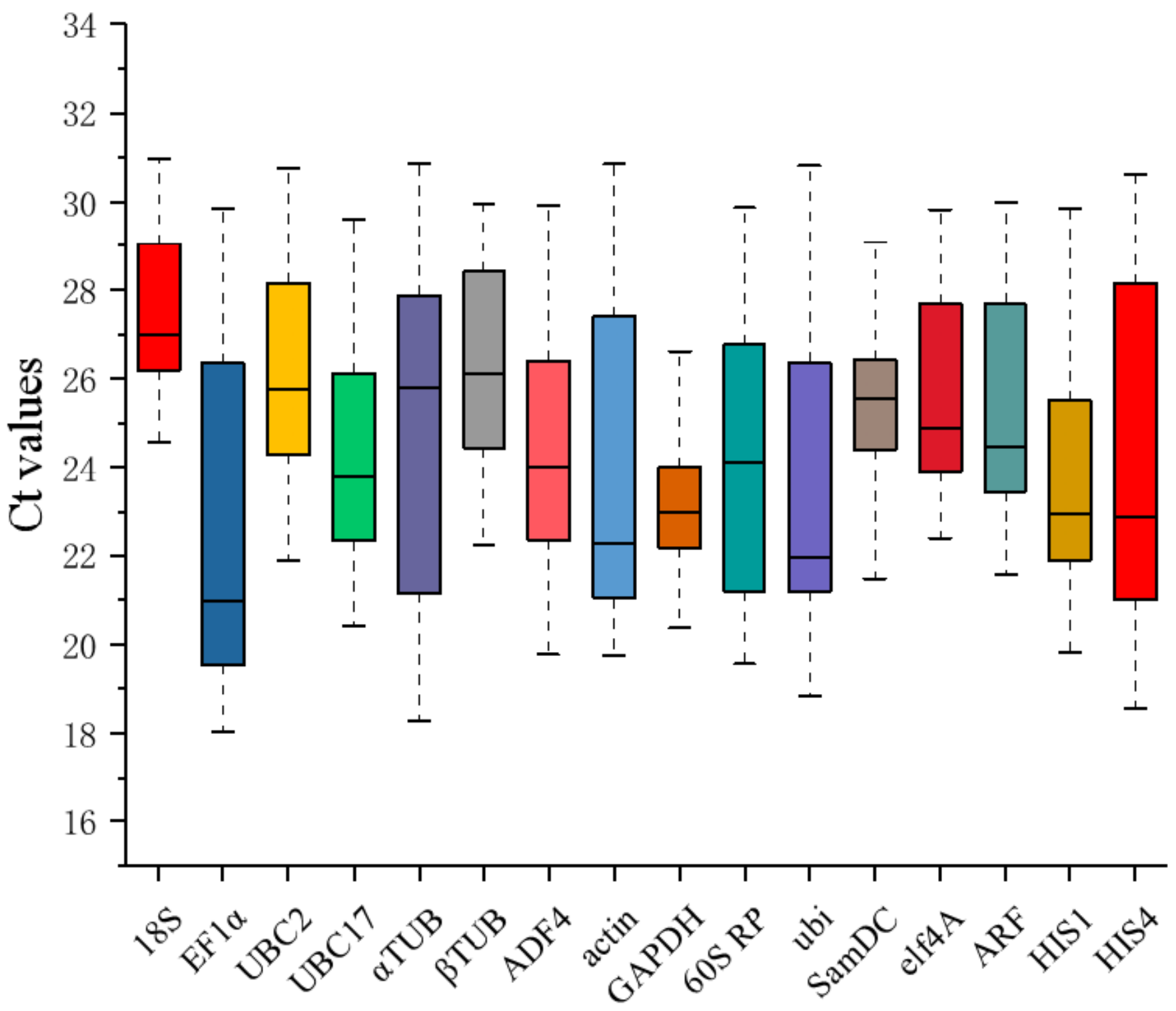

Figure 2 
Fig. 2. Distribution of CT values of 16 candidate genes in all samples. Boxplot graph showing maximum, minimum values, medians and $25 / 75$ percentiles.
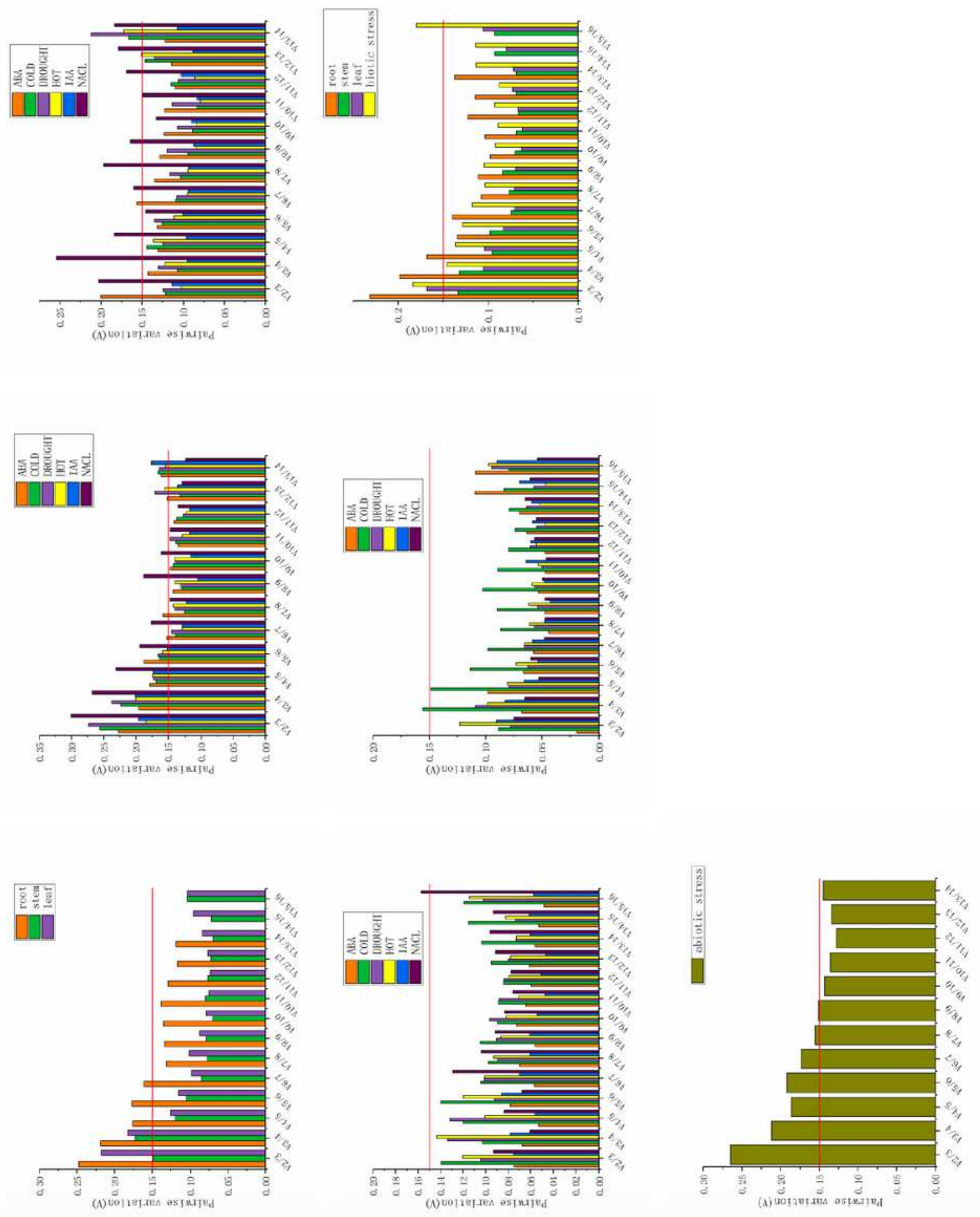

\section{Figure 3}

Fig. 3. (a) Pairwise variation (V) analysis of 14 candidate genes under abiotic stress in different tissues; (b) Pairwise variation (V) analysis of 14 candidate genes under different abiotic stress; (c) Pairwise variation $(V)$ analysis of 14 candidate genes in root tissue under biotic stress; (d) Pairwise variation $(V)$ 
analysis of 14 candidate genes in stem tissue under abiotic stress; (e) Pairwise variation (V) analysis of 14 candidate genes in leave tissue under abiotic stress; (f) Pairwise variation (V) analysis of 14 candidate genes under biotic stress; (g) Pairwise variation (V) analysis of 14 candidate genes under abiotic stress.
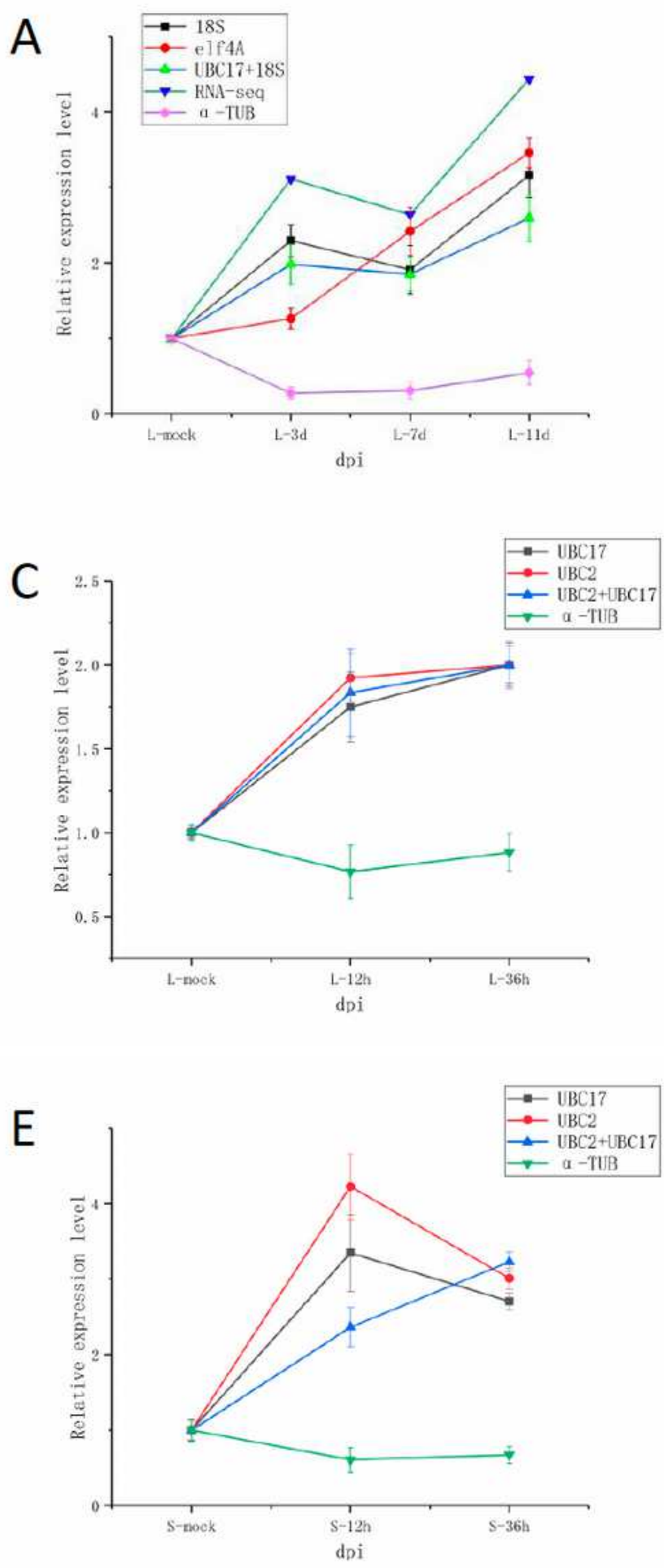
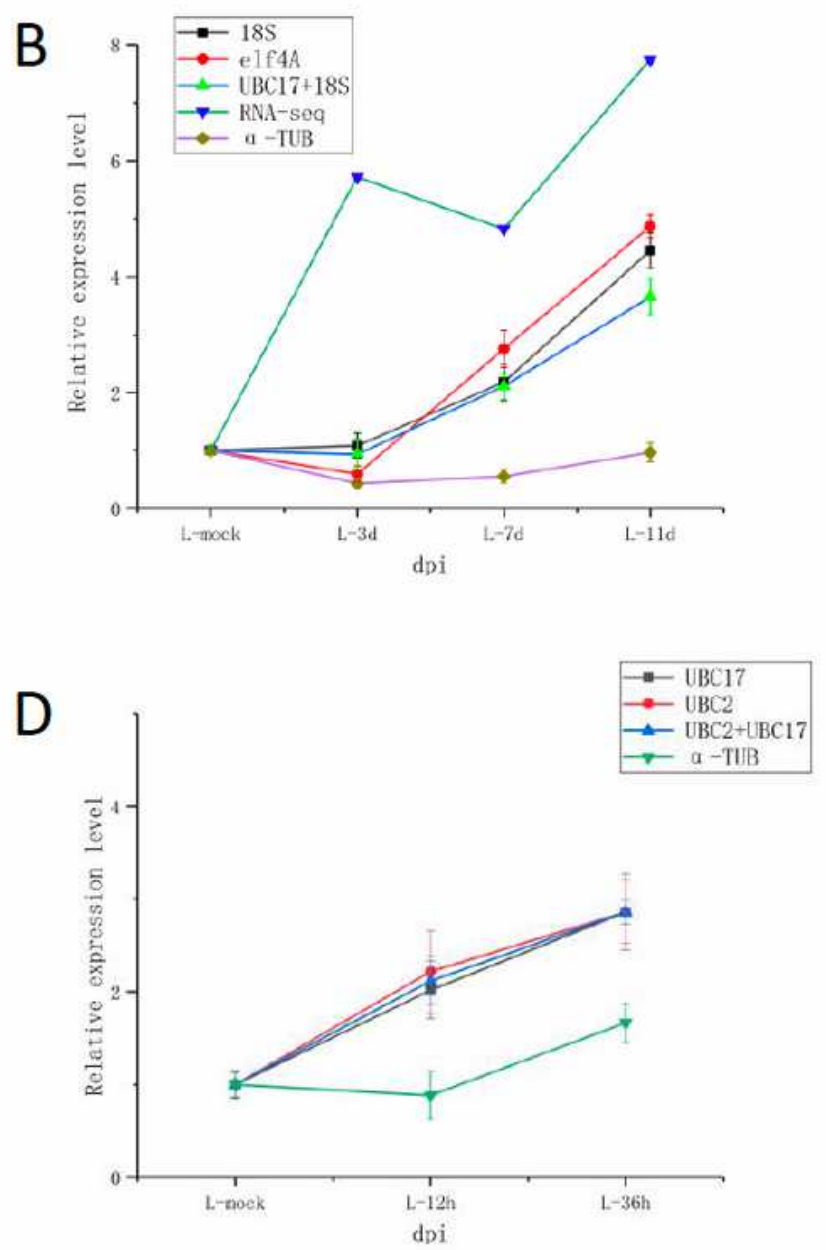

\section{Figure 4}

Fig. 4. (a) Relative expression level of PsaCPK 3 under BYDV GAV infection in leave tissue and corresponding transcriptome data RNA seq; (b) relative expression level of Psa HSP70 3 under BYDV GAV 
infection in leave tissue; (c) relative expression level of Psa HSP70 3 under salinity stress in leave tissue; (d) relative expression level of PsaCPK 3 under salinity stress in leave tissue;(e) relative expression level of Psa HSP70 3 under salinity stress in stem tissue. 